NBER WORKING PAPER SERIES

\title{
NEW EVIDENCE THAT FULLY ANTICIPATED MONETARY \\ CHANGES INFLUENCE REAL OUTPUT AFTER ALL
}

Robert J. Gordon

Working Paper No. 361

\author{
NATIONAL BUREAU OF ECONOMIC RESEARCH \\ 1050 Massachusetts Avenue \\ Cambridge MA 02138 \\ June 1979
}

This paper is a revised version of a comment on Robert Barro's studies of unanticipated money and economic activity, presented at the NBER's conference on Rational Expectations and Economic Policy, Melvin Village, New Hampshire, October 13, 1978; forthcoming in S. Fischer, ed., Rational Expectations and Economic Policy (University of Chicago Press for NBER, 1980). This research has been supported by the National Science Foundation and is part of the NBER's research program in Economic Fluctuations. I am grateful to Jon Frye for research assistance, and to Stanley Fischer, Allan Meltzer, and David Small for comments on earlier versions of these comments. Any opinions expressed are those of the author and not those of the National Bureau of Economic Research. 
New Evidence that Fully Anticipated Monetary

Changes Influence Real Output After All

SUMMARY

A new empirical study of the relation between money, nominal income, prices, and real output in postwar quarterly U.S. data rejects virtually all of the conclusions reached by Robert Barro in his three papers on the topic (AER 1977, JPE 1978, and 1978 conference paper with Mark Rush). A distinction is drawn between the Lucas-Sargent-Wallace (LSW) theory that only unanticipated monetary changes influence real output, and the orthodox view that anticipated monetary changes influence real output in the short run during the interval of adjustment of prices to the monetary change. The LSW proposition requires for its validity a contemporaneous and equiproportionate response of the expected price level to the anticipated level of money or nominal GNP, whereas the orthodox approach requires that price expectations depend at least partly on the past history of prices rather than entirely on the expected level of nominal demand.

The results uniformly support the orthodox approach. The Livingston expectations series exhibits a highly significant response to past price changes, and only a slight response to current expectations about nominal GNP or money. The actual inflation rate also depends heavily on past price changes, with an insignificant impact of current expectations of nominal GNP, or money. The equations that relate real output to the deviation of changes of nominal income (both anticipated and unanticipated) from past price changes fit the data significantly better than Barro's approach using current and lagged values of money "surprises." The pure version of the LSW approach relating real output only to current surprises is decisively rejected.

Robert J. Gordon Department of Economics Northwestern University Evanston, Illinois 60201

(312) 492-3616 


\section{INTRODUCTION}

The point of departure for this series of empirical papers by Robert Barro is the proposition, associated with the names of Lucas, Sargent, and Wallace (LSW), that real output is independent of predictable movements in the money supply. 'The innovative and controversial feature of this hypothesis is not that money is neutral in the long run, for this proposition-"the natural rate" hypothesis (NRH)-was accepted by a substantial majority of economists by the time the LSW hypothesis was advanced. Instead, if it is to have any independent content, the LSW hypothesis must state that systematic monetary stabilization has no effect on output in the short-mon.

If valid, the LSW hypothesis would undermine much of the existing literature on stabilization policy. Regular countercyclical activist intervention, implemented as a predictable response to movements in output or unemployment, would be both futile and unnecessary. ${ }^{2}$ The entire optimal control branch of the stabilization policy literature, and existing demonstrations that particular derivative or proportional feedback control formulae are more effective stabilizers than a constant-growth-rate-rule, would be rendered irrelevant. 'The concept of the political business cycle, and of the manipulation of the economy for electoral purposes, would be relegated to a museum for obsolete economic ideas. ${ }^{4}$

Because of the radical implications of the LSW hypothesis for the theory and practice of stabilization policy, it is understandable that macroeconomists sfould have eagerly awaited a convincing empirical verification. But 
it is surprising to me that the series of papers by Robert Barro would be regarded as providing any such empirical support. "For the Barro papers provide no test at all of the short-mon neutrality proposition of LSW that would distinguish it from the widely-accepted Iong-mun "natural rate" neutrality hypotheris CNRHL. Barro's papers fail to provide any support for the LSW hypothesis for three separate reasons:

1. There is no explicit empirical test of the leading competing hypothesis upon which the orthodox stabilization literature rests its case-that short-run inertia and stickiness of price adjustment allows any change in nominal income (whether anticipated or unanticipated) to affect real output in the short run. The Gradual Adjustment of Prices (GAP) hypothesis is fully compatible with the long-run neutrality of $\mathrm{NRH}$ if the inflation rate gradually but continuously accelerates whenever output exceeds its "natural" level. GAP combined with NRH implies that any permanent shift in the growth rate of nominal income is initially divided between faster growth in both output and prices, but that gradually the output stimulus vanishes until higher inflation has fully absorbed the nominal income acceleration.

2. Far from attempting to distinguish the LSW and NRH-GAP hypotheses, Barro compares as determinants of output on the one hand unanticipated money change, and on the other hand row money change. The statistical defeat of the latter appears to be the only evidence put forth to support the ISW hypothesis. But this is like setting up a World Series between the Yankees and a team of geriatric invalids. The real Yankee-Dodger World Series for the output-determination trophy (see below) pits unanticipated money change as one explanatory variable versus the deviation between actual 
money change and an adaptively-adjusting expected price change as the competing variable. Barro's correlations between the output gap and row money change make no contribution whatsoever to distinguishing the dubious LSW hypothesis from the widely accepted NRH, because any such long-run Ielation between a real variable (output) and a nominal variable (raw money change) would violate the NRH. We know that the acceleration of monetary growth between the 1950 s and 1970s did not produce a "permanent economic high," but this fact does not by itself constitute evidence against the short-run potency of stabilization policy.

3. Not only do Barro's output and unemployment equations fail to provide any evidence supporting the LSW hypothesis, but, worse yet, his price equations strongly undermine the theoretical rationale of the LSW hypothesis by validating the competing NRH-GAP hypothesis. Barro estimates that the full adjustment of prices to changes in the money supply takes between four and six years, while the formation of anticipations about monetary changes takes only a single quarter. ${ }^{6}$ For LSW to be valid, any fully anticipated monetary change that raises nominal income must raise prices simultaneously, since the hypothesis states that real output must remain unaffected. Thus Barro's price equations fail to validate the one-quarter lag between actual money and the price level that would be necessary to confirm the required contemporaneous response of the price level to an anticipated money change. I In the long interval between the singlequarter adjustment of expectations about monetary change, and the fourth or sixth year required for the full price response to occur; anticipated monetary change can affect real output. The net resilt of Barro's research on 
prices, with its finding of a 24-quarter time interval between a monetary change and the full adjustment of prices, seems to amount to little more than a reconfirmation of my earlier study (1975) which found a 28-quarter lag.

2. A STATEMENT OF THE IDENTIFICATION PROBLEM

The Lucas supply function on which the LSW hypothesis is based states that the gap $\left(H_{t}\right)$ between $\log$ output $\left(Q_{t}\right)$ and $\log$ natural output $\left(Q_{t}^{*}\right)$ depends on the difference between the actual and expected rate of change of prices $\left(p_{t}-p_{t}^{e}\right):$

(1) $\quad H_{t}=\alpha\left(p_{t}-p_{t}^{e}\right)+\varepsilon_{t}$,

where $\varepsilon_{t}$ is a stochastic error term with mean zero.

Most current econometric models which generate orthodox conclusions about the short-run potency of stabilization policy determine prices by an expectational Phillips curve equation that relates the same variables as follows:

(1') $\quad p_{t}=p_{t}^{e}+B H_{t}+\eta_{t}$.

The difficulty of distinguishing between the LSW hypothesis based on (1) and the orthodox conclusions based on ( $l^{\prime}$ ) is evident in comparing the two equations, since $\left(l^{\prime}\right)$ is just an inverted version of (1), and vice versa.

If expectations are rational, and the $p_{t}^{e}$ term in (1) incorporates all past information (including the serial correlation properties of $p_{t}$ ), then the forecast error $\left(p_{t}-p_{t}^{e}\right)$ should be serially uncorrelated, leading to the criticism that equation (1) cannot explain the high degree of positive serial correlation observed in actual data on $\mathrm{H}_{t}$. However, the LSW hypothesis 
can be rescued from this line of criticism if the output gap depends at least partly on its own past values:

$$
H_{t}=\alpha\left(p_{t}-p_{t}^{e}\right)+\sum_{i=1}^{\infty} \theta_{i} H_{t-i}+\varepsilon_{t} .
$$

For instance, Blinder and Fischer (1978) have rationalized (2) on the grounds that a positive price "surprise" will lead firms to raise sales more than production, decumulating inventories, and then to rebuild their stocks of inventories gradually in future periods. Thus, even if there is no price surprise in period $t+1$, the output gap $\left(\mathrm{H}_{t+1}\right)$ would depend positively on the output gap last period $\left(\mathrm{H}_{t}\right)$ and in earlier periods as we11.

It is possible to derive Barro's estimated equation linking output to a distributed $\mathrm{lag}$ of past monetary changes from equation (2), if we begin by calling upon the "quantity identity" to provide a connection between the rates of change of prices, money, velocity, and real output:

$$
\text { (3) } \quad p_{t} \equiv m_{t}+v_{t}-q_{t} \text {. }
$$

Further, if prices are known to clear markets, then a rational expectation of the price level will equal the difference between the expected level of nominal income and output, with all level variables in logs:

$$
E_{t-1}\left(P_{t}\right)=E_{t-1}\left(M_{t}\right)+E_{t-1}\left(V_{t}\right)-E_{t-1}\left(Q_{t}\right)
$$

When we substitute the expectation of the output gap equation (2) into (4), we obtain:

$$
E_{t-1}\left(P_{t}\right)=E_{t-1}\left(M_{t}\right)+E_{t-1}\left(V_{t}\right)-Q_{t}^{*}-\sum_{i=1}^{\infty} \theta_{i} H_{t-1} .
$$


Using the definitions that relate expectations of the rates of change of variables to expectations of their levels, (5) is equivalent to:

$$
p_{t}^{e}=m_{t}^{e}+v_{t}^{e}-q_{t}^{*}+H_{t-1}-\sum_{i=1}^{\infty} \theta_{i} H_{t-i}
$$

When the difference between (3) and (6) is substituted into (2), we can solve by recursion to obtain a direct relation between the current output gap and current and lagged "surprises" in the growth of both money and velocity.

(7) $H_{t}=\sum_{i=0}^{\infty} \frac{\phi}{1+\alpha}\left[\alpha\left(m-m^{e}+v-v^{e}\right)_{t-i}+\varepsilon_{t-i}\right]$,

where $\phi_{0}=1$.

Note in (6) that the expected change in the price level depends on expected nominal GNP growth, adjusted both for the growth of natural output $\left(q_{t}^{*}\right)$ and for the influence of any non-zero output gaps that may have occurred in previous periods. Thus in this version of the LSW model that allows for persistence in the output gap, as in equation (2), the expected change in prices does not simply echo the expected growth of nominal GNP. Depending on whether the total influence of the lagged gap terms is positive or negative, a one-percentage-point increase in expected nominal GNP growth could be accompanied by an increase in expected price change of either more or less than one percentage point. 10

The estimated output equation in Table 1 of Barro-Rush (1979) can be viewed as an empirical representation of equation (7). Barro-Rush find that monetary surprises $\left(m-m^{e}\right)$ in ten past quarters are significant in explaining output. Significant positive serial correlation is present in the estimated 
Barro-Rush output equations, corresponding to the presence in (7) of the past error terms $\varepsilon_{t-i}$. The only important difference is that Barro-Rush agents are assumed to be able to predict velocity with precise accuracy, while their uncanny predictive powers do not extend to perfect foresight about the money supply--thus only monetary surprises are included in their estimated output equation rather than the more general form (7) which calls for real output to depend on surprises in nominal GNP growth.

How can the LSW hypothesis that real output is independent of anticipated changes in nominal GNP be distinguished from the NRH-GAP hypothesis that anticipated nominal GNP changes influence real output during the interval of price adjustment? Clearly, no empirical research on the hypotheses can make headway if it simply involves a comparison of the Lucas supply equation in (1) with the expectational Phillips curve in (1'), since the two equations are just inverted versions of each other. Instead, a different approach is required. Leaving aside the lagged gap terms, it is apparent in (6) that the LSW approach requires expected inflation to be based on expectations of nominal GNP growth, whereas the essence of the competing NRH-GAP hypothesis is that inertia in the adjustment of prices prevents an instantaneous response of expected price change to expected nominal GNP change. In its most extreme version, NRH-GAP would state that expected inflation responds only to past inflation, with no response at all to anticipated demand conditions:

$$
p_{t}^{e}=\sum_{i=1}^{\infty} \lambda_{i} p_{t-i}
$$

A more rational version of the formation of expectations under the NRH-GAP hypothesis would take account both of inertia and of knowledge of the 
structure of $\left(1^{\prime}\right)$, that is, of the partial dependence of inflation on shifts in demand $\left(\mathrm{H}_{\mathrm{t}}^{\mathrm{e}}\right) \mathbf{:}^{11}$

$$
p_{t}^{e}=\sum_{i=1}^{\infty} \lambda_{i} p_{t-i}+b H_{t}^{e}
$$

We can compare (9) with a version of the LSW price expectation equation that is similar to Barro's own price equation. Substituting the relation between the output gap and lagged "surprises" from equation (7) into (6), we obtain:

$$
p_{t}^{e}=m_{t}^{e}+v_{t}^{e}-q_{t}^{*}+\sum_{i=1}^{\infty} u_{t-i} \sum_{j=1}^{i} r_{j} \phi_{i-j},
$$

where $u_{t}=[1 /(1+\alpha)]\left[\alpha\left(m-m^{e}+v-v^{e}\right)_{t}+\varepsilon_{t}\right]$, and $\gamma_{1}=\left(1-\theta_{1}\right)$, while $\gamma_{i}=-\theta_{i}$ for $i>1$.

Two main differences are evident in comparing the NRH-GAP approach in (9) with the implied LSW equation in (10). First, the influence of past history is represented in (9) by actual price change, but in (10) by past nominal GNP surprises. Second, given the past history of surprises, (10) states that there should be a contemporaneous and equiproportionate "jump" in the expected rate of price change to any "jump" in anticipated nominal GNP growth, whereas in (9) there is no such implication.

\section{ESTIMATED EQUATIONS THAT DISTINGUISH LSW FROM NRH-GAP}

The present section proposes three tests of the relative explanatory power of the two competing hypotheses of the formation of price expectations, fitted to U.S. postwar quarterly data.

(1) Using as the dependent variable the Livingston data on the price expectations of a panel of economic forecasters, (9) and (10) can be estimated directly. 
(2) Employing as price data the same GNP deflator series used by Barro, the alternative expectations equations (9) and (10) can be substituted into ( $1^{\prime}$ ) to test their relative ability to explain the postwar behavior of the inflation rate.

(3) Employing as output data the same real GNP series used by Barro, the LSW supply equation (7) can be compared with an alternative NRH-GAP version obtained by substituting (9) into ( $\left.1^{\prime}\right)$ and solving for the current output gap.

1. Explaining Inflation Expectations. The central assumption of the LSW short-run neutrality hypothesis is a unit-elastic contemporaneous response of the expected price level to any change in the expected level of nominal GNP, holding constant the influence of past nominal GNP "surprises". Translated into rates of change, as in equation (10) above, the partial elasticity of the expected inflation rate to the expected rate of change in nominal GNP is unity. The validity of this assumption, as well as the relation between price expectations and past nominal GNP surprises, can be tested on the price expectations of the Livingston panel of economic forecasters, as compiled by Carlson (1977).

A series for expected nominal GNP growth $\left(y_{t}^{e}=m_{t}^{e}+v_{t}^{e}\right)$ can be developed by fitting an autoregressive equation analogous to Barro's expected money equation, with past changes in money and in the share of government spending in GNP $\left(g_{t}\right)$ as additional explanatory variables:

$$
\begin{aligned}
& \mathrm{y}_{t}=\underset{[4.21]}{.010}+\underset{[3.85]}{.367} \mathrm{y}_{t-1}+\underset{[0.61]}{.064} \mathrm{y}_{t-2}-\underset{[-1.77]}{.182} \mathrm{y}_{t-3}-{ }_{[-1.41]}^{.148} \mathrm{y}_{t-4}
\end{aligned}
$$

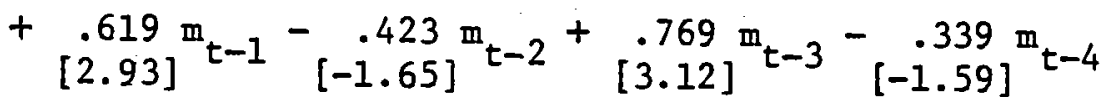

$$
\begin{aligned}
& +\underset{[2.45]}{.090} g_{t-1}-\underset{[-1.93]}{.060} g_{t-2} \\
& R^{2}=.430 \quad \text { S.E.E. }=.0105 \text { D.W. }=2.13 \\
& \text { Sample Period = 1948:Q1 - 1978:Q1. }
\end{aligned}
$$


Then the fitted values from equation (11) can be used to test the validity of equation (10), which states the LSW proposition that expected inflation should depend on the current expectation of nominal GNP growth, adjusted for the effect of past nominal GNP surprises.

The basic estimate of the LSW price expectation equation (10) is presented in Table 1, column (1). There is little support in the 1954-75 U.S. data for the ISW hypothesis, since the elasticity of expected inflation to expected nomiaal GNP growth (holding constant lagged nominal GNP surprises) is not 1.0 but only .124 , indicating that forecasters expect 88 percent of an anticipated change in nominal GNP to take the form of a change in real output. Stated another way, the Livingston forecasters act as if they believe the ISW hypothesis to be false. ${ }^{12}$

The influence of the nominal GNP surprise last period $\left(y-\hat{y}^{e}\right)_{t-1}$ is separated in Table 1 from earlier surprises, since in equation (10) the first lag is the only coefficient the sign of which can be determined a priori (the $\theta_{i}$ terms should be fractions less than unity, so that the first lag should have the positive coefficient $1-\theta_{1}$ ). In column (1) it appears that the coefficients on both the first lagged surprise and on earlier surprises are insignificant.

All equations in this paper allow for two extra variables representing "supply shocks" that cause inflation to change relative to expected inflation for any given level of the real output gap $\left(\mathrm{H}_{t}\right)$. The first is a dummy variable for the 1971-74 Nixon-era price controls, and the second is a proxy for the influence of foreign prices on U.S. domestic prices $\left(p_{t}^{F}\right)$. While the NIXCON dummy has the wrong sign in column (1), the foreign price term is extremely important. This variable may partially be acting as a 
proxy for lagged domestic prices, which play an important role in explaining price expectations in the NRH-GAP approach.

Column (2) of Table 1 presents the same equation corrected for the positive serial correlation present in column (1). This correction alters the sign on the NIXCON dummy, reduces the foreign price coefficient to a more plausible size, and yields the conclusion that the response of expected price change to anticipated nominal GNP growth is zero, not unity as postulated by the LSW approach. The lagged nominal GNP surprise terms are insignificant, as in column (1).

Columns (3) and (4) present parallel results, replacing the role of anticipated and unanticipated changes in nominal GNP by anticipated and unanticipated changes in the money supply (MI), using the Barro-Rush money supply equation to provide estimates of $\hat{\mathrm{m}}_{t}^{\mathrm{e}}$. The results in both columns indicate a response to anticipated monetary change of zero, rather than the required elasticity of unity. The main difference between the nominal GNP and money results is the significant explanatory role of the distributed lag of past unanticipated monetary change in columns (3) and (4).

Columns (5) and (6) present the alternative results for equation (9), the statement of expectation formation under the NRH-GAP hypothesis. The corrected results in column (6) indicate that expectations respond to past price changes with an elasticity that is insignificantly different from unity, when the domestic and foreign price contributions are added together. Expectations are also influenced by the level of the real output gap and by the Nixon price controls. In fact, it is interesting that the coefficients on the price control dummy are almost identical in columns (2), (4), and (6). In this final equation it appears that the Livingston 
forecasters act as if they believe that prices adjust gradually to changes in demand conditions. The mean lag on the past change in the CPI is 9.9 quarters, and a full 24 quarters of past price information is regarded as relevant in the formation of expectations; thus the lag distributions on lagged unanticipated monetary changes in column (4) and on the lagged CPI changes in column (6) are approximately the same.

Is there any role for nominal GNP or money changes in explaining the price expectations of the Livingston forecasters? When added to the equation in column (5), the nominal GNP variables (both current anticipated and lagged unanticipated changes) are jointly insignificant (the F-value for joint significance is 0.38 , compared with the 5 percent critical value of 3.11). However, the money supply variables are jointly significant (F-value of 4.75), while the lagged consumer price variables are very significant jointly when added to the money equation in column (3) (F-value of 14.9). Thus a complete explanation of the Livingston inflation expectations series appears to require use of data on lagged changes both in the CPI and in money.

There is no need to choose the "best" equation in Table 1, since the results are entirely consistent with the NRH-GAP approach. Expected price changes do not respond at all to anticipated changes in nominal GNP or money, implying that these anticipated changes influence real output. Further, the lag coefficients on unanticipated money in columns (3) and (4) also support the hypothesis of gradual price adjustment. Recall that in the Barro-Rush money equation $\hat{\mathrm{m}}_{t}^{\mathrm{e}}$ depends almost entirely on $\mathrm{m}_{t-1}$. Thus the lagged surprise terms represent nothing more than a five-year distributed lag on actual changes in the money supply. 
2. Explaining the Inflation Rate. Equation (1') above states that the difference between the actual and expected inflation rates is a function of the real output gap. If inflation expectations are formed by the LSW hypothesis, represented by equation (10) above, then equation (1') would be completely consistent with the LSW hypothesis that real output is independent of anticipated changes in nominal GNP. The rate of change of prices in this case would be calculated by substituting (10) into ( $\left.1^{\prime}\right)$ :

$$
p_{t}=m_{t}^{e}+v_{t}^{e}-q_{t}^{*}+\sum_{i=1}^{\infty} u_{t-i} \sum_{j=1}^{i} \gamma_{j} \phi_{i-j}+B H_{t}+n_{t} .
$$

The alternative hypothesis that price expectations are formed in a manner that is consistent with the gradual adjustment of prices would involve substituting (9) above into ( $\left.1^{\prime}\right)$ :

$$
\mathrm{P}_{t}=\sum_{i=1}^{\infty} \lambda_{i} \mathrm{p}_{t-i}+(b+\beta) \mathrm{H}_{t}+\eta_{t} \text {. }
$$

In Table 2 column (1) displays the direct estimate of equation (12), while column (2) is a "money-only" version which assumes that the actual and expected growth rates of velocity are both zero. Column (3) represents an estimate of equation (13).

Most of the results in Table 2 duplicate those in Table 1 . The elasticity of price change to current expectations of nominal GNP or money growth is not unity, as required by the LSW hypothesis, but only .14 in column (1) and .05 in column (2). As in the previous Table, the money-only version fits better than the nominal GNP version; the coefficients on the NIXCON and foreign price variables in the money-only equation are significant and have the expected sign; and the long distributed lag on unanticipated monetary changes indicates that a full seven years is required for prices to adjust to actual changes in money. 
Column (3) represents an estimate of equation (13) above, the NRHGAP hypothesis that inflation depends on the history of past price changes, as well as on current demand and supply factors. The coefficient on the current output gap indicates that the short-run Phillips curve has a slope of . 27 when inflation is expressed at an annual rate; for instance, holding constant the history of inflation and the values of the other variables, a 5 percentage point positive output gap implies an inflation rate that is 1.4 percentage points faster at an annual rate than when the output gap is zero. The Nixon control effect is significant in the expected direction in columns (2) and (3), with a cumulative impact of either -3.0 or -2.1 percent in 1971-72 followed by an offsetting rebound in 1974 .

The pattern of coefficients on the Nixon control dumny and the foreign price proxy can be explained as follows. Comparing Columns (1) and (3), we note that the coefficient on the foreign price term in the former is twice the value in column (3); given the positive correlation between $\mathrm{p}_{t}$ and $\mathrm{p}_{t}^{\mathrm{F}}$, the large coefficient on $\mathrm{p}_{t}^{\mathrm{F}}$ in column (i) represents an attempt by the computer to find a variable that can provide the required explanatory power of the missing lagged $\mathrm{P}_{t-i}$. On the other hand, the $\mathrm{P}_{t}^{\mathrm{F}}$ variable grows much more rapidly than $P_{t}$ in 1974 , setting a natural limit on the size of the coefficient on $\mathrm{p}_{t}^{F}$. Further, the rapid growth period of $\mathrm{P}_{t}^{F}$ is partly collinear in 1974 with the "rebound" portion of the Nixon control dumm, forcing down the coefficient on NIXCON in equations like that in column (I) where lagged $\mathrm{P}_{t-i}$ is missing and $\mathrm{P}_{t-i}^{\mathrm{F}}$ is required to have a large coefficient. Notice that in column (2), where the sum of coefficients on $\mathrm{P}_{t-i}^{F}$ is smaller than in column (3), the coefficient in NIXCON is correspondingly larger. 
Is there any role for current expectations of changes in nominal GNP or money in explaining price behavior, given the past history of prices? When the past history of prices is added to the equation of either columns (1) or (2), the coefficient on anticipated changes in either nominal GNP or money is insignificantly different from zero. On the other hand, lagged unanticipated changes in nominal GNP or money do contribute significantly to the explanation of price change when added to the autoregressive equation in column (3). This suggests that, while the results in Table 2 reject the required unitary response of price change to anticipated nominal GNP or money change, there is a remaining role for demand changes in explaining price change that is not completely represented by the $H_{t}$ variable in column (3).

3. Explaining the Output Gap. A final comparison of the LSW and NRHGAP approaches involves the estimation of output equations. This allows us to test directly the conflicting predictions that only unexpected nominal GNP or monetary changes influence real output (LSW), versus aZI nominal GNP or monetary changes-whether anticipated or not-influence real output during the interval required for price adjustment (NRH-GAP). None of the unemployment or output equations in the three Barro empirical papers provide any test of this alternative hypothesis.

The LSW output hypothesis is represented by equation (7) above: 


$$
H_{t}=\sum_{i=0}^{\infty} \frac{\phi_{i}}{1+\alpha}\left[\alpha\left(m-m^{e}+v-v^{e}\right)_{t-i}+\varepsilon_{t-i}\right]
$$

Thus the output gap $\left(H_{t}\right)$ responds to the current and lagged "surprise" in nominal GNP growth. The competing NRH-GAP hypothesis can be rewritten as an output equation when (13) is solved for the output gap:

$$
H_{t}=\frac{1}{1+b+\beta}\left(m_{t}+v_{t}-q_{t}^{*}+H_{t-1}-\sum_{i=1}^{\infty} \lambda_{i} p_{t-i}-\eta_{t}\right),
$$

where we use the identity $p_{t} \equiv y_{t}-q_{t}$ and the definitions of $q_{t}^{*}$ and $H_{t-1}$. Thus the competing hypothesis is not that "only unexpected nominal GNP changes matter", but rather that "real output depends on actual nominal GNP changes adjusted for the past history of prices." The longer prices take to adjust to an acceleration of nominal GNP growth, the longer a real output gap can persist, even if nominal GNP behavior is fully conticipated.

A minor difference between Barro's papers and our empirical investigation of output behavior involves the treatment of "natural" output (Q*). Barro ignores previous research on $Q^{*}$, uses the $\log$ of real output as his dependent varfable, and attempts to capture the influence of $Q^{*}$ on the righthand side of his equation by including a time trend and his peculiar MIL variable (see Small, 1978). A preferable procedure is to take advantage of the research of Perloff and Wachter (1978) which takes explicit account of the production function linking $Q^{*}$ to capital, energy, and "natural" labor input. The growth of $Q^{*}$ has slowed in the 1970 s, due to the deceleration in the growth of capital and energy input relative to labor input, and the use of $a^{*} Q^{*}$ series taking account of this deceleration avoids the misspecification involved in Barro's extraneous MIL variable. Thus the dependent variable in all of the output equations in Tables 3 and 4 is the real output gap, 
$\mathrm{H}_{t}=\log \left(Q_{t}\right)-\log \left(Q_{t}^{*}\right)$

Table 3 reports estimates of equations (14) and (15) and related equations involving the growth of nominal GNP. Because of the need to use a long distributed lag of past nominal GNP changes, and because quarterly nominal GNP data are unavailable prior to 1947, all equations in Table 3 share a common sample period running from 1954 to 1978.

Although both the ISW and NRH-GAP hypotheses suggest that nominal GNP growth (i.e., money growth and velocity growth) should be relevant for explaining the output gap, Barro's work has concentrated on the behavior of money growth alone. To provide equations analogous to Barro's, Table 4 repeats each equation from Table 3, with money growth replacing nominal GNP growth. Because of the availability of money supply data before 1947, the equations in Table 4 have been estimated over the longer 1949-78 sample period.

If column (1) in Table 3 is viewed as a test of equation (1), a "pure" version of the LSW hypothesis without any influence of lagged "surprise" terms, then that view is rejected by the estimated equation. The coefficient on unexpected nominal GNP change is insignificant, and the explanatory power of the equation is weak. Following a more general approach in which lagged "surprises" are allowed to influence the level of real output, as in equation (14), column (2) exhibits the effect of adding lagged values of unexpected nominal GNP growth. While the fit of the equation is improved somewhat, its standard error is still large and its Durbin-Watson statistic is extremely low. Most important is the fact that a full 27 quarters of lagged "surprise" data are significant (this was the longest lag distribution examined). While persistence of the output gap is consistent with 
the NRH-GAP hypothesis, it strains credulity to imagine a mechanism by which a nominal GNP "surprise" could still influence real output seven years later as required for column (2) in Table 3 to be consistent with the LSW hypothesis.

In contrast to the weak explanation of the output gap exhibited in columns (1) and (2), the estimate of the NRH-GAP approach in equation (15) is presented in column (3). Not only is the estimated standard error only one-tenth of the LSW error in equation (1), but all of the coefficients are consistent with the theoretical specification and with the corresponding inflation equation in Table 2. Using column (3) of Table 2, we can compare the estimated coefficients with column (3) of Table 3 :

Table 2

$\begin{array}{cr}b+\beta & .068 \\ \frac{1}{1+b+\beta} & .936 \\ \Sigma \lambda \perp & .744 \\ \text { NIXCON } & -.021 \\ \mathrm{P} & .157\end{array}$

Table 3

$$
\begin{array}{r}
.882 ; .931 \\
.794 ; .752 \\
-.022 ;-.020 \\
.154 ; .146
\end{array}
$$

Column (3) can be interpreted as saying that "given the inherited values of inflation and the output gap, the elasticity of the output gap to a fully anticipated acceleration in nominal income growth is 88 percent." While the contrast between the results in columns (1) and (2) on the 
one hand, and in column (3) on the other hand, is sufficiently dramatic to establish the main argument of the paper, some critics may claim that the attractive characteristics of column (3) are due to the presence of the lagged dependent variable on the right-hand side of the equation. 16 The NRH-GAP output equation (15) can be.solved recursively to eliminate the lagged dependent variable; this transformation makes the output gap a function of a distributed lag of the other independent variables. The results of estimating the transformed equation are exhibited in columns (4) and (5), without and with a correction for positive serial correlation. We note that the NRH-GAP equation in column (4), in which both anticipated and unanticipated nominal GNP changes matter, improves the fit of both ISW equations in columns (1) and (2) by a factor of three. Although the equation in column (4) exhibits significant positive serial correlation, the transformed equation in column (5) appears to have roughly the same sums of coefficients on lagged income and price change.

In order to provide results that are comparable directly to the BarroRush quarterly output equations, Table 4 duplicates the equations in Table 3 with money change everywhere replacing nominal GNP change. As in Table 3, column (1) in Table 4 indicates that there is no statistically significant relation between the real output gap and the current money "surprise," thus rejecting the "pure" version of the LSW hypothesis. Only when a long series of lagged "surprises" is included is the joint effect of the surprise terms significant, and the shape of the lag distribution seems to be quite sensitive to a correction for positive serial correlation (compare columns 2 and 3 ). Confirming Table 3, we note that the estimated version of the NRH-GAP 
equation (15) in column (4) of Table 4 explains the output gap data much better than either of the unexpected money equations; the standard error is lower by a factor of almost three (compare columns 2 and 4 ). Even without the "help" of the lagged dependent variable, the versions of the NRH-GAP equations in columns (5) and (6) outperform the lagged "surprise" equations in columns (2) and (3).

An interesting feature of the output results is a'consistent difference in the explanatory power of the nominal GNP and money equations. Holding constant the sample period, the LSW equations fit better for money "surprises" than for nominal GNP "surprises," whereas the NRH-GAP equations fit better for nominal GNP change than for money change. 17 Why? Two related conjectures appear to account for this pattern. First, anticipated changes in velocity "matter", thus accounting for the better performance of the NRH-GAP equations using nominal GNP growth as an explanatory variable. Second, the nominal GNP equation used to estimate $\hat{y}_{t}^{e}$ does a better job than Barro's equation used to estimate $\hat{m}_{t}^{e}$. Small's research (1978) has shown that

Barro treats as unanticipated important instances of money change that could have been anticipated by economic agents at the time. If anticipated changes in money influence real output, as implied by the three right-hand columns of Table 4, then much of the explanatory power of Barro's "money surprise" variable may actually represent the influence of anticipated monetary changes. If we accept the implication that Table 3 is a preferable comparison of the LSW and NRH-GAP hypotheses, because Barro's money equation used to create $\hat{m}_{t}^{e}$ in Table 4 is misspecified, then we can regard the poor performance of the LSW equations in columns (1) and (2) of Table 3 as analogous to the 
poor performance of Small's (1978) unemployment equation when an improved specification of $\hat{\mathrm{m}}_{t}^{\mathrm{e}}$ is used. The conclusion that the equations in Table 4 are misspecified would also explain the inconsistent pattern of coefficients on the Nixon control and foreign price variables in that table.

\section{INTERPRETATIONS OF THE RESULTS}

Virtually none of the conclusions of Barro's three papers (1977)(1978)(1979) emerge intact when viewed from the perspective of Tables 1 through 4.

1. According to Barro, "the hypothesis that forms the basis of this empirical study is that only unanticipated movements in money affect real economic variables like the unemployment rate or the level of output" (1977, p. 101, emphasis added). Yet Table 4 provides equations in which the real output gap depends on both anticipated and unanticipated money changes. Further, not only does Table 4 deny that only unanticipated money changes matter, but also it contains the finding that current money surprises do not matter at all in explaining real output.

2. Barro (1978, pp. 565-6) states as a "basic hypothesis" that "perceived movements in the money stock . . . imply equiproportionate, contemporaneous movements in the price level." Yet Table 2 strongly rejects this basic hypothesis and finds instead that the contemporaneous response of price change to perceived movements in money, holding constant the influence of past monetary surprises, has an elasticity of only 0.05 , and to perceived movements in nominal GNP an elasticity of only 0.14. Approximately seven years is required for the full equiproportionate adjustment to take place.

3. Contradicting the LSW hypothesis of policy impotence, the 
Barro-Rush (1979, Table 1, column 2) quarterly results find a significant impact on real output of government spending, whether anticipated or not. Table 3 confirms a role for changes in velocity, whether caused by policy or nonpolicy influences, in that the versions of the NRH-GAP equations using nominal GNP fit considerably better than those using only monetary changes (see footnote 17 ).

4. Barro claims (1978, p. 573) that "there is no indication from these calculations of a downward effect of controls on the price level." Yet Tables 2 and 3 report the consistent result that the Nixon controls held down the price level by a statistically significant 2.1 percent, almost exactly the same as my most recent published estimate (1977, p. 263). Barro makes no mention in his quarterly estimates of other supply shift elements that might have affected real output and the price level, but Tables 2 and 3 report a significant and consistent impact of a proxy for the influence of foreign prices on U. S. domestic prices.

5. Barro-Rush (1979) admit "some lack of robustness in the price equation" and the possibility of "some misspecification of this relation." Several of their variables lose significance when a correction for serial correlation is performed, and the lagged effects of money "surprises" in the price equation are not consistent with those in the output equation. In contrast the NRH-GAP inflation equation in Table 2 , column (3), yields parameter estimates that are almost identical with those estimated in the NRH-GAP output equation (Table 3, column 3). The respective mean lags in response to past price changes are almost identical--9.4 and 9.9 quarters. 


\section{CONCLUSIONS}

The finding in this paper that fully anticipated changes in nominal GNP and money influence real output appears to reinstate the orthodox view that "changes in money matter in the short run, whether anticipated or not." The "pure" version of the LSW hypothesis that relates the output gap only to curpent surprises in money or nominal GNP seems to be decisively rejected. A modified LSW approach is developed in which constructed "surprise" variables have a statistically significant impact on real output when entered as a long distributed lag, a lagged effect that has been rationalized recently in theoretical models developed by Lucas (1975) and Blinder and Fischer (1978). Thus this paper does not purport to claim that lagged surprises have no influence on real output.

No such claim is made because no such claim is necessary. Once it has been shown, as in this paper, that fully anticipated changes in nominal GNP and money do influence real output, then the role of past unanticipated changes ceases to be an interesting question. Lucas, Sargent, and Wallace are, after all, the proponents of the dogmatic and radical position that the set of factors $X$ that influence real output can be subdivided into $X 1$ and $X 2$, and that only XI matters. AlI that is necessary to refute this position is to show that $X 2$ also matters, as in this paper. The finding of statistically significant effects of lagged surprises is of no importance because the orthodox view of stabilization policy is completely compatible with a role for innovations in nominal income as a determinant of the real output gap. 
In this sense the present debate contains the same asymmetry as the early 1960s debate over whether "only money matters." Nonmonetarists in that episode felt that they could rest their case by showing that fiscal policy also matters, since they viewed positive effects of monetary policy as consistent with their position. In the same way, proponents of the NRH-GAP approach can rest their case by showing that anticipated nominal GNP changes also matter, since they view a positive impact of unanticipated changes as consistent with their position.

An important theme running through recent discussions of the short-run and long-run neutrality hypotheses is the difficulty of identifying the structure of an economic model from aggregative time series data, because several models may be compatible with a time-series dependence of, for instance, nominal GNP growth on lagged monetary changes (Sargent, 1976). More informally, "you can't get a structure out of a time series." For this reason there can be no pretense in this paper that the apparent timeseries dependence of real output on current and lagged fully anticipated changes in money can identify the particular structural model that introduces inertia into the process of price adjustment. For instance, there is no necessity to tie the NRH-GAP hypothesis to any particular model of implicit contracts, layoffs, or customer markets, any more than Barro is required to identify the particular theory that allows his lagged monetary surprises to influence real output.

Whether or not one is satisfied with the underlying theory of Lucas supply functions or price inertia is quite irrelevant in the current asymmetric debate. Instead an appeal to the facts is both necessary and 
sufficient to settle the issue. The Sargent (1976) "observational equivalence" conundrum does not prevent a choice between the LSW and NRH-GAP approaches, even though both hypotheses implicitly make real output and price change a function of a distributed lag of past nominal GNP or monetary change, because the LSW alternative requires for its validity strong restrictions that can be statistically rejected (e.g., that the coefficient on anticipated nominal GNP change of price change is unity and of real output is zero, holding constant past monetary surprises).

In all of this the roles of price flexibility and rational expectations have been frequently confused by economists writing on the short-run neutrality issue. The rational expectations hypothesis can be interpreted as stating that "people respond to processes in the economy." If one of those processes with which people are familiar is the three-year staggered wage contract, then a rational expectation of the inflation rate will be based at least partly on the past history of prices to which the present rate of price change is mechanically connected. Many economists who have readily adopted the assumption that agents are completely rational seem curiously reluctant to accept the parallel assumption that agents act In their own self interest. Instead of dismissing models of disequilibrium price adjustment as involving "a failure of agents to realize perceived gains from trade," economists should devote more serious attention to the possibility that existing contractual arrangements may represent an efficient response to uncertainty and the real costs of bargaining.

It is hard to avoid the conclusion that the earlier Barro of gradual price adjustment and quantity constraints as at last emerged 
triumphant over the more recent classical equilibrium Barro. ${ }^{19}$ It now appears fruitless to continue to promote a set of dogmatic propositions that "X2 does not matter" while hiding ostrich-like from the pervasive reality of price inertia that invalidates those propositions. Instead, a much more productive line of research would be to provide a convincing theoretical explanation of price inertia itself, as well as variations in the inertia parameter across markets, countries, and time. Precisely what factors explain why some products are bought and sold in spot auction markets, while other products have prices that are administered and changed infrequently? Why was the post-1973 division of nominal GNP between price and output change more favorable in Germany than in the U. S.? Why was the same division more favorable between 1929 and 1933 in Europe than in the U. S.? What are the sources of the U.S. institutions of staggered and decentralized long-term wage contracts, with only partial cost-of-living escalation, and what factors have caused changes in those institutions and thus in the U. S. price inertia parameter? 


\section{REFERENCES}

Robert J. Barro, "Unanticipated Money Growth and Unemployment in the United States," American Economic Review, vol.67 (March, 1977), pp. 101-15. , "Unanticipated Money, Output, and the Price Level in the United States," Joumal of Political Economy, vol. 86 (August 1978), pp. 549-80.

and Stanley Fischer, "Recent Developments in Monetary Theory," Journal of Monetary Economics, vol. 2 (April 1976), pp. 133-68. and Herschel Grossman, Money, Employment, and Inflation

(New York: Cambridge University Press, 1976). and Mark Rush, "Unanticipated Money and Economic Activity," This Volume.

Alan S. Blinder, "Comment on Barro-Rush," This Volume. and Stanley Fischer, "Inventories, Rational Expectations, and the Business Cycle," M.I.T. working paper, June, 1978.

John A. Carlson, "A Study of Price Forecasts," Annals of Economic and Social Measurement, vol. 6 (Winter, 1977), pp. 27-56.

Stanley Fischer and J. Phillip Cooper, "Stabilization Policy and Lags," Joumal of Political Economy, vol. 81 (July/August, 1973), pp. 847-77.

Robert J. Gordon, "The Impact of Aggregate Demand on Prices", Brookings Pcopers on Economic Activity, vol. 6 (1975, no. 3), Pp. 613-62. , "Can the Inflation of the 1970s be Explained?" Brookings Papers on Economic Activity, vol. 8 (1977, no. 1), pp. 253-77. , Macroeconomics (Boston: Little-Brown, 1978). 
Robert E. Hall and David M. Lilien, "Efficient Wage Bargains under Uncertain Supply and Demand," National Bureau of Economic Research working paper no. 206, December, 1978.

Robert E. Lucas, Jr., "An Equilibrium Model of the Business Cycle," Joumal of Political Economy, vol. 83 (December 1975), pp. 1113-44. , "Econometric Policy Evaluation: A Critique," in K. Brunner and A. Meltzer, eds., The Phizlips Curve and Labor Markets (New York: North-Holland, 1976), pp. 19-46.

William D. Nordhaus, "The Political Business Cycle," Review of Economic Studies, vol. 42 (April, 1975), pp. 169-90.

Jeffrey M. Perloff and Michael L. Wachter, "A Production Function Nonaccelerating Inflation Approach to Potential Output," forthcoming in the proceedings of the Carnegie-Rochester conference held in Rochester, April, 1978.

Thomas J. Sargent, "The Observational Equivalence of Natural and Unnatural Rate Theories of Macroeconomics," Joumal of Political Economy, vol. 84 (June 1976), pp. 631-40.

David H. Small, "A Comment on Robert Barro's 'Unanticipated Money Growth and Unemployment in the United States, "' 1978 working paper, forthcoming in the American Economic Review. 
1. The first half of the present paper by Robert Barro and Mark Rush (1979) presents a summary and extensions of a previous paper (1978) based on annual data; the second half contains estimates of some of the same equations for quarterly data. Since the present paper does not contain an explicit statement of the hypotheses being tested, nor of the alternative hypotheses that are implicitly rejected, the discussant is forced to refer back to the earlier Barro papers (1977) (1978). These comments treat together the combined results of the three papers.

2. Perfect price flexibility, necessary for the LSW hypothesis to be valid, would insulate real output from any anticipated shock. For instance, the 1974 quadrupling of the price of oil, while it would reduce the "natural" level of output, could have not effect on the gap between actual and "natural" output, once the price hike was announced.

3. This would include a series of papers by the conference organizer, e.g., Fischer and Cooper (1973).

4. See Nordhaus (1975).

5. Thus I was startled to read in Blinder's comment (1979), that "... Keynesians have been searching for an obvious flaw in [Barro's] methodology. That one has not been found suggests that the basic flaw, if indeed there is one, is far from obvious." The present comment argues that the flaw is patently obvious--Barro's equations are simply irrelevant in determining the role of anticipated changes in policy, because his specification cannot distinguish the LSW hypothesis from the competing price-inertia hypothesis on which the orthodox view of stabilization policy is based. 
6. Table 2 of the quarterly Barro-Rush (1979) results exhibit a six-year adjustment $\mathrm{lag}$ in the price equation when no correction is made for serially correlated residuals, and a four-year lag in the equations reestimated with an adjustment for second-order serial correlation.

7. Barro's text explicitly denies any connection between the long price-adjustment lags and "explanations for price stickiness of the 'disequilibrium' or contracting variety." This denial appears to rest entirely on the discrepancy between the adjustment lags in the output and price equations. Yet there is another explanation of the inconsistent lags, namely his misspecification of both the output and price equations (see below).

8. The Barro-Rush results thus provide the needed refutation of the erroneous criticism of my (1975) conclusions that appears in Barro (1978, P. 571): "The effect of anticipated money movements on the price level can be virtually instantaneous at the same time that unanticipated movements... affect the price level only with a long lag." Far from being instantaneous, the full response of prices to an anticipated monetary change in Barro-Rush requires a time span of 23 quarters.

9. In the following, upper-case letters represent levels of the logs of variables, and lower-case letters represent their percentage rates of change. Equation (I) can be compared to the supply function used in the discussion of the LSW hypothesis in Barro-Fischer (1976, P. 157):

(a) $\quad H_{t}=\alpha\left(P_{t}-E_{t}\left(P_{t+1}\right)\right)+\varepsilon_{t}$.

In (a) output decisions depend on a discrepancy between this period's price level and the expected price level next period, with intertemporal speculation 
as the motive for the supply response. Since Barro's present empirical work revolves around an unanticipated discrepancy between this period's actual money supply and the expectations for this period based on information available zast period, the underlying supply function must be:

$$
\text { (b) } \quad H_{t}=a\left(P_{t}-E_{t-1}\left(P_{t}\right)\right)+\varepsilon_{t} \text {. }
$$

This is the version of the Lucas supply function considered by Blinder and Fischer (1978, p. 3). The use of (b) implies an assumption of imperfect information about the aggregate price level in the current period by individual agents. Then ( 1 ) in the text follows from (b) when we define:

$$
P_{t}=P_{t}-P_{t-1} \quad \text { and } \quad P_{t}^{e}=E_{t-1}\left(P_{t}\right)-P_{t-1} \text {. }
$$

10. Notice that if the output gap depends only on current price surprises, with no influence of the history of the output gap, so that $\theta_{i}=0(i=1, \ldots, \infty)$, then equation (6) reduces to: $p_{t}^{e}=m_{t}^{e}+v_{t}^{e}-q_{t}^{*}+H_{t-1}$. Thus, if a positive monetary surprise in period $t-1$ had caused a positive output gap, then a rational expectation of a perfectly flexible price level in period $t$ would make an allowance for the extra price "jump" needed to eliminate the previous gap.

11. The parameter $b$ in (9) is not necessarily identical to $B$ in $\left(1^{\prime}\right)$, because $B$ is an uncertain parameter that shifts in response to structural changes and past policy actions, as suggested by Lucas (1976). Thus b represents an estimate of the unknown $\beta$.

12. The sample period ends in 1975:Q4, the final observation provided by Carlson (1977) for the dependent variable. The starting date of 1954:Q1 
in this and subsequent tables is motivated by the need to use up to 28 quarters of information on lagged values of nominal GNP, expected nominal GNP, unexpected nominal GNP, and the GNP deflator.

13. In, this and subsequent tables, only two variables are included to represent supply shifts. The Nixon control durmy is defined so that its coefficient indicates the cumulative effect on the level of prices during the period 1971:Q3-1972:Q4, and it is constrained to force the effect of the removal of controls in 1974 exactily to balance the initial restraining effect (see note $c$, Table 1). The foreign price variable tests the hypothesis that U. S. prices of exports and import substitutes respond to foreign prices. In my current research I have also found that other supply shift variables, including changes in the effective minimum wage rate and in various tax rates, have significant effects on the rate of change of U. S. prices. The limited scope of this paper prevents an exploration of the full set of supply shift variables.

In Table 1 the dependent variable for quarter $t$ is the Livingston forecast made in the last month of the quarter for the price level six months later. Thus the equations in columns (1) and (2) assume that the forecasters know the actual values of nominal GNP and the money supply through quarter $t-1$, and that they are able to make an accurate estimate of the output gap in quarter $t$. Given the persistence of the output gap demonstrated in Table 3 below, an ability to guess $H_{t}$ correctly in the middle of the current quarter seems reasonable.

14. A 28-quarter lag distribution (the current quarter and 27 lagged quarters) was the maximum length used in this study.

15. Just as the Barro-Rush unemployment equations in their Table 1 
ignore 1947 and 1948 because of the peculiar relation between output and unemployment during that interval, the present paper omits 1947 and 1948 from the output gap equations.

16. Note that the equation has other desirable features, despite the presence of the lagged dependent variable, particularly the consistency of the estimated coefficients between Tables 2 and 3 .

17. The respective standard errors for the shorter 1954-78 sample period for the five equations in Table 3 when money is inserted in place of nominal GNP are, respectively:

$\begin{array}{ccccc}(1) & (2) & (3) & (4) & (5) \\ .0264 & .0187 & .0080 & .0117 & .0075\end{array}$

18. A start in this direction has been made recently by Hall and Lilien (1978).

19. For the earlier vintage, see especially Barro and Grossman (1976, Chapters 2 and 5). 
Alternative Equations for the Livingston Expected Inflation Series ${ }^{a}$

Sample Period: 1954:Q1-1975:Q4

Independent Variables $b, c$

(1)

(2)

(3)

(4)

(5)

(6)

$$
\begin{aligned}
& \hat{y}_{t}^{e}-q_{t}^{*} \\
& \hat{m}_{t}^{e}-q_{t}^{*} \\
& \left(y-\hat{y}^{e}\right)_{t-1} \\
& \left(m-\hat{m}^{e}\right)_{t-1} \\
& k \\
& \sum_{i=2}^{k} \psi_{i}\left(y-\hat{y}^{e}\right)_{t-i} \\
& k \\
& \sum \psi_{i}\left(\mathbb{m - m ^ { e }}\right)_{t-i} \\
& k \\
& \sum_{i=1}^{k} \lambda_{i} p_{t-i}^{C} \\
& H_{t}
\end{aligned}
$$$$
.124 \quad .015
$$$$
\text { [3.94] [1.32] }
$$

\section{NIXCON}

$\sum_{i=1}^{K} \omega_{i} p_{t-i}^{F}$

$\begin{array}{cccccc}.011 & -.006 & -.000 & -.007 & -.001 & -.006 \\ {[2.43]} & {[-3.73]} & {[-0.13]} & {[-3.98]} & {[-0.22]} & {[-4.08]}\end{array}$

$\left[\begin{array}{ll}-.021 & -.047 \\ {[-0.29]} & {[-0.98]}\end{array}\right.$

$\left[\begin{array}{lc}-.023 & .006 \\ {[-0.84]} & {[0.75]}\end{array}\right.$

$\begin{array}{cc}.110 & .052 \\ {[2.07]} & {[1.63]}\end{array}$

$\begin{array}{cc}.210 & .221 \\ {[0.80]} & {[0.58]} \\ (3.1 \mid 0) & (15.5 \mid 0)\end{array}$

$\begin{array}{cc}.934 & 1.70 \\ {[6.15]} & {[5.21]} \\ (2.5 \mid 20) & (11.3 \mid 22)\end{array}$

$\begin{array}{llllll}.269 & .106 & .208 & .109 & .140 & .065\end{array}$

$\left[\begin{array}{llllll}{[16.9]} & {[4.59]} & {[13.0}\end{array}\right]\left[\begin{array}{lll}.88 & {[4.65]} & {[2.48]}\end{array}\right.$

$\begin{array}{llllll}\left(\left.3.0\right|_{7}\right) & \left(\left.2.9\right|_{7}\right) & \left(\left.3.6\right|_{6}\right) & \left(\left.3.5\right|_{5}\right) & \left(\left.2.9\right|_{6}\right) & \left(\left.2.1\right|_{2}\right)\end{array}$

\begin{tabular}{lllllll}
\hline $\mathrm{R}^{2}$ & .868 & .986 & .937 & .986 & .951 & .988 \\
S.E.E. & .0018 & .0006 & .0013 & .0006 & .0011 & .0006 \\
D.-W. & 0.4 & 1.8 & 0.4 & 1.7 & 0.4 & 1.8 \\
0 & & $\begin{array}{c}.978 \\
{[43.7]}\end{array}$ & & $\begin{array}{c}.880 \\
{[17.2]}\end{array}$ & $\begin{array}{c}.790 \\
{[12.0]}\end{array}$ \\
\hline
\end{tabular}

[0.00] indicates $t$ ratio.

$(0.010)$ indicates mean $\mathrm{lag}$ and the furthest significant lag coefficient for a variable entered as a distributed lag. All lag distributions are assumed to lie along a third-degree polynomial, and all are constrained to equal zero in the final quarter. 
Notes to Table 1

a. The dependent variable is the six-month expected change in the CPI, from Carlson (1977, Table 1), with alternate quarters interpolated from the reported data.

b. Each equation also contains a constant term.

c. The independent variables are as follows:

\begin{tabular}{|c|c|}
\hline$y_{t}$ & $\begin{array}{l}\text { Fitted value of the quarterly rate of change of nominal } \\
\text { GNP, see equation (11) in the text. }\end{array}$ \\
\hline & $\begin{array}{l}\text { Fitted value of the quarterly rate of change of } \mathrm{MI} \text {, } \\
\text { using the Barro-Rush quarterly money supply equation. }\end{array}$ \\
\hline & $\begin{array}{l}\text { The quarterly rate of change of "natural" real GNP }\left(Q^{*}\right) \text {. } \\
\text { See the explanation of } \mathrm{H}_{t} \text {. }\end{array}$ \\
\hline & $\begin{array}{l}\text { The quarterly rate of change of the all-item Consumer } \\
\text { Price Index. }\end{array}$ \\
\hline $\mathrm{H}_{t}$ & $\begin{array}{l}\text { The percentage } G N P \text { gap }\left(\log Q_{t}-\log Q_{t}^{*}\right) \text {, where } Q_{t} \text { is } \\
\text { real GNP, and } Q_{t}^{*} \text { is taken from Gordon }(1978 \text {, Table } B-2) \\
\text { for the period } 1947-70 \text { and from Perloff-Wachter }(1978) \text { for } \\
\text { the period } 1971-78 \text {. }\end{array}$ \\
\hline NIXCON & $\begin{array}{l}\text { A dummy variable set equal to } 1 / 6 \text { during the six quarters } \\
1971: Q 3 \text { through } 1972: Q 4 \text { and to }-1 / 4 \text { during the four } \\
\text { quarters } 1974: Q 2 \text { through } 1975: Q 1 \text {. }\end{array}$ \\
\hline & $\begin{array}{l}\text { The quarterly rate of change of the average of the } \\
\text { import and export deflators from the U. S. National } \\
\text { Income Accounts. }\end{array}$ \\
\hline
\end{tabular}


TABLE 2

Alternative Equations for the

Rate of Change of the GNP Deflator

Sample Period: 1954:Q1-1978:Q1

Independent Variables $b, c$

(1)

(2)

(3)

$$
\begin{aligned}
& \hat{y}_{t}^{e}-q_{t}^{*} \\
& \hat{m}_{t}^{e}-q_{t}^{*} \\
& \left(y-\hat{y}^{e}\right)_{t-1} \\
& \left(m-\hat{m}^{e}\right)_{t-1}
\end{aligned}
$$

$\sum_{i=2}^{R} \psi_{i}\left(y-\hat{y}^{e}\right)_{t-i}$

$\sum_{i=2}^{R} \psi_{i}\left(\hat{I-m^{e}}\right)_{t-i}$

$\mathrm{K}$

$\sum_{i=1} \lambda_{i} P_{t-i}$

$$
.045
$$

$i=1$

.076

$[0.64]$

.856

[2.77]

(11.3|23)

$\mathrm{H}_{\mathrm{t}}$

.030

[2.16]

2.41

[5.68]

$$
(10.2 \mid 27)
$$

\section{NIXCON}

$\sum_{i=1}^{R} w_{i} p_{t-i}^{F}$

$-.005$

[-0.71]

[11.7]

$(2.7 \mid 7)$
$-.006$

.744

[3.96]

$(9.4 \mid 17)$

.068

$[5.40]$

$-.021$

$[-3.44]$

$[-3.47]$

$\left[\begin{array}{l}.116 \\ 3.28]\end{array}\right.$

$(3.1 \mid 7)$
.157

[3.02]

$(2.3 / 4)$

\begin{tabular}{lccc}
\hline $\mathrm{R}^{2}$ & .772 & .847 & .818 \\
$\mathrm{S.E.E.}$ & .0032 & .0026 & .0028 \\
D. W. & 1.65 & 2.21 & 1.93
\end{tabular}

All notes to Table 1 also apply to this table. 


\section{TABLE 3}

Equations Explaining the Output Gap $\left(\mathrm{H}_{t}\right)$

Using Changes in Nominal GNP $\left(y_{t}\right)$

Sample Period: 1954:Q1-1978:Q1

(1)

(2)

(3)

(4)

(5)

$$
\begin{aligned}
& y_{t}-\hat{y}_{t}^{e} \\
& \sum_{i=0}^{k} \psi_{i}\left(y-\hat{y}^{e}\right)_{t-i} \\
& y_{t}-q_{t}^{*} \\
& \sum_{i=0}^{K} \delta_{i}\left(y-q^{*}\right)_{t-i} \\
& k \\
& \sum \lambda_{i=1}{ }^{P} t-i \\
& H_{t-1}
\end{aligned}
$$$$
.232
$$$$
\text { [0.75] }
$$

$$
\begin{gathered}
6.71 \\
{[2.83]} \\
(11.7(27)
\end{gathered}
$$

$-.700$

[-3.97] $(9.9 \mid 17)$

$$
\begin{gathered}
11.2 \\
{[27.3]}
\end{gathered}
$$

$(10.0 \mid 27)(8.5 \mid 27)$

$\left[\begin{array}{r}.931 \\ {[73.3]}\end{array}\right.$

$-11.8$

$-10.5$

[-19.0] [-7.98]

$(13.9 \mid 27)(11.8 \mid 27)$

$\begin{array}{lccccc}N I X C O N & .065 & .068 & .019 & .094 & .021 \\ K & {[1.22]} & {[1.30]} & {[3.42]} & {[5.97]} & {[2.71]} \\ \sum_{i=1} \omega_{i} P_{t-i}^{F} & -.234 & -.270 & -.136 & .021 & -.483 \\ & (1-1.15] & {[-1.28]} & {[-2.60]} & {[0.15]} & {[-4.11]} \\ & (15.2 \mid 6) & (14.0 \mid 7) & (2.5 \mid 4) & (-77 \mid 7) & (4.6 \mid 7)\end{array}$

$\mathrm{R}^{2}$

$.242 \quad .325$

$(15.2 \mid 6)$

$(14.017)$

$(2.5) 4$

$(-77 \mid 7)$

$(4 . 6 \longdiv { 7 ) }$

$\begin{array}{llllll}\text { S.E.E. } & .0268 & .0256 & .0027 & .0072 & .0029 \\ \text { D.-W. } & 0.1 & 0.1 & 1.91 & 0.4 & 1.65\end{array}$

$\rho$ 
TABLE 4

Equations Explaining the Output Gap $\left(H_{t}\right)$ Using Changes in the Money Supply $\left(m_{t}\right)$

Sample Period: 1949:Q1-1978:Q1

\begin{tabular}{|c|c|c|c|c|c|c|}
\hline Independent Variables & (1) & (2) & (3) & (4) & (5) & (6) \\
\hline $\mathrm{m}_{t}-\hat{\mathbf{m}}_{t}^{e}$ & $\begin{array}{c}.630 \\
{[0.98]}\end{array}$ & & & & & \\
\hline$\sum_{i=0}^{i} \psi_{i}(m-\hat{m})_{i-i}$ & & $\begin{array}{c}8.42 \\
{[3.89]} \\
(-5.0 \mid 27)\end{array}$ & $\begin{array}{c}15.7 \\
{[2.57]} \\
(7.1 \mid 14)\end{array}$ & & & \\
\hline$m_{t}-q_{t}^{*}$ & & & & $\begin{array}{c}.910 \\
{[5.81]}\end{array}$ & & \\
\hline$\sum_{i=0}^{K} \delta_{i}\left(m-q^{*} L_{t-i}\right.$ & & & & & $\begin{array}{l}7.93 \\
{[6.54]} \\
(4.6 \mid 11)\end{array}$ & $\begin{array}{c}7.24 \\
{[2.97]} \\
(5.1 \mid 10)\end{array}$ \\
\hline$\sum_{i=1}^{k} \lambda_{i} p_{t-i}$ & & & & $\begin{array}{l}-.977 \\
{[-2.56]} \\
(6.0 \mid 12)\end{array}$ & $\begin{array}{l}-4.52 \\
{[-3.90]} \\
(7.3 \mid 27)\end{array}$ & $\begin{array}{l}-5.85 \\
{[-2.40]} \\
(11.5 \mid 17)\end{array}$ \\
\hline$H_{t-1}$ & & & & $\begin{array}{l}.887 \\
{[28.8]}\end{array}$ & & \\
\hline NIXCON & $\begin{array}{c}.099 \\
{[1.68]}\end{array}$ & $\begin{array}{l}-.001 \\
{[-0.00]}\end{array}$ & $\begin{array}{c}.011 \\
{[0.42]}\end{array}$ & $\begin{array}{c}.032 \\
{[1.78]}\end{array}$ & $\begin{array}{l}-.018 \\
{[-0.52]}\end{array}$ & $\begin{array}{c}.002 \\
{[0.06]}\end{array}$ \\
\hline$\sum_{i=1}^{k} \omega_{i} p_{t-i}^{F}$ & $\begin{array}{l}-.048 \\
{[-0.22]} \\
(41 \mid 7)\end{array}$ & $\begin{array}{l}-.623 \\
{[-2.71]} \\
(5.1 \mid 7)\end{array}$ & $\begin{array}{l}-.344 \\
{[-1.42]} \\
(6.7 \mid 7)\end{array}$ & $\begin{array}{c}.025 \\
{[0.20]} \\
(1.3 / 3)\end{array}$ & $\begin{array}{l}-1.04 \\
{[-4.32]} \\
(3.7 \mid 7)\end{array}$ & $\begin{array}{l}-.603 \\
{[-2.20]} \\
(4.6 \\
(4)\end{array}$ \\
\hline $\mathrm{R}^{2}$ & .137 & .459 & .913 & .931 & .745 & .931 \\
\hline S.E.E. & .0314 & .0251 & .0100 & .0091 & .0175 & .0090 \\
\hline D. - W. & 0.1 & 0.2 & 1.5 & 1.6 & 0.3 & 1.7 \\
\hline$\rho$ & & & $\begin{array}{c}.923 \\
{[25.9]}\end{array}$ & & & $\begin{array}{c}.860 \\
{[18.2]}\end{array}$ \\
\hline
\end{tabular}

All notes to Table 1 also apply to this table. 